\title{
Tribuna Académica
}

91

Encuentro №. 102,91-107, 2015

\section{Camino de vida en la investigación del hecho religioso $^{1}$}

\section{Ricardo Falla, s.j.}

El tema de esta plática es Camino de vida en la investigación del hecho religioso. Se trata de una perspectiva autobiográfica, no sólo por ser más amena para una presentación hablada, sino porque no se entiende bien la actividad investigativa, sin tener en cuenta al sujeto que la hace. Se trata del hecho o fenómeno religioso, entendido ampliamente, de modo que abarque la espiritualidad, como experiencia aún no estructurada, ni conceptual, ni ritual, ni institucionalmente, y aún no traducida en acción social y política. Lo que define a esa experiencia es una adhesión total que implica a la persona y al grupo. Puede abarcar también la experiencia del ateísmo, si conlleva esta totalidad. Sin embargo, somos conscientes que, como dijo Lévi Strauss, la fenomenología de la religión no es posible o es muy dificultosa. Y por fin, se trata de investigación. La investigación incluye práctica y teoría. Práctica, como la recolección de datos, el método seguido, el tiempo de análisis y redacción, hasta la publicación. Teoría, como todo el andamiaje que sustenta las hipótesis y pretende dar una explicación universal, a la vez que una mirada de predicción. Voy a intentar ir tejiendo todos estos hilos en tres pasos que suponen tres etapas del camino de vida. Creo que aparecerá que el hilo conductor es el acento en la experiencia. ${ }^{2}$

Ponencia presentada en el Congreso de ritualidades y religiosidades, realizado en San Cristóbal de las Casas el 28 de octubre de 2015.

Antropólogo y sacerdote jesuita.

2 Una reflexión parecida, que podría complementar esta, hice para la clausura del Congreso Nacional de Antropología y Etnología en la Rectoría de la UAM, Ciudad de México, el 25 de septiembre de 2010: Antropología y Violencia: una experiencia personal. 


\section{El fenómeno religioso visto desde el poder y la liminalidad: Quiché Rebelde (Falla, 2007)}

Provengo de una familia católica guatemalteca, conservadora política y religiosamente, de clase alta, como dicen. Mi madre murió siendo yo niño. Mi vocación a la Compañía de Jesús, pues soy jesuita, nació como una plantita en esa familia. A los 19 años, es decir, en 1951, entré en la orden, después de oposición continuada, aunque no tajante de parte de mi padre. Dejé mi familia y la carrera que había iniciado en los Estados Unidos. Fue un primer paso hacia la libertad de condicionamientos sociales a la hora de hacer antropología. Pero la antropología entonces para mí era algo desconocido. Creo que ni había oído esa palabra rara. Cada uno de ustedes puede recordar dónde conoció a esa señora llamada antropología.

Nos formamos - con otros compañeros jesuitas - en humanidades clásicas y en filosofía dentro de parámetros de iglesia tridentina, léase, conservadora, en el Ecuador. Esa formación tenía como referencia doctrinal inconsciente el Concilio de Trento del siglo 16 y el Vaticano 1 del siglo 19. Sin embargo, durante esos cinco años del Ecuador, tuvimos a un formador que influyó mucho en nosotros por su método de análisis de los textos clásicos de Virgilio y Sófocles, que estudiábamos en el original: latín y griego. Nos enseñó cómo se analizaban esos autores universales, "destripando" el contenido, poniéndonos en la escena "como si presentes nos hallásemos” y dejándonos impactar por el sentimiento estético, todo lo cual llevaba a una formación integral de la persona, no sólo respecto al aspecto religioso, sino a los valores humanos, en general. No nos daba reglas de cómo se hacía. Sólo lo hacía él y lo hacíamos nosotros, me refiero al análisis. Entonces, la formación y el método, que era parte de esa formación, entraba, decía él, "por ósmosis". Se llamaba el P. Aurelio Espinosa Pólit, ecuatoriano, muy conocido en su país. Había estudiado en Cambridge. Pero no era Cambridge, creo, lo que le daba esa fuerza formadora de la mente y del corazón, sino la asimilación del método espiritual de Ignacio de Loyola. Su inteligencia no era la de un genio, pero era profundamente humano y nos hacía vibrar. De él saqué el método de análisis de casos, de análisis de textos, de análisis de esas narraciones riquísimas que uno frecuentemente encuentra como joyas en la vida del pueblo. Ustedes lo saben por experiencia (para una biografía, ver: Miranda Ribadeneira, 1974).

Pero nuestros parámetros mentales eran todavía, como dije, tridentinos. No fue sino al llegar a teología en Innsbruck, Austria, cuando se operó en mí una doble, llamémosla, crisis epistemológica. Eso fue en 1961. Ambas fueron de distinto tipo, pero estuvieron vinculadas. La primera, se dio cuando, movido por las palabras y el ejemplo de un jesuita compañero mío que venía de Cataluña, llamado Ferrán Manresa, me decidí a trabajar con pico y pala en medio de los migrantes españoles que llegaban a Centroeuropa a construir carreteras. Este compañero había tenido la experiencia obrera en su tierra, previa a los estudios de Teología y me animó a probarla. En efecto, se me cambió el mundo 180 grados. De gente que pasaba desde el carro viendo a los trabajadores de carreteras sudando, a trabajador que recibía cigarrillos de turistas que simpatizaban con nosotros. Desde esa experiencia se nos hizo - porque éramos varios que íbamos de América Latina a estudiar a Austria - se 
nos hizo ¡vergonzosa!, hasta caérsenos la cara de vergüenza, la alianza que habíamos tenido con las trece familias de El Salvador, aceptando pasar vacaciones en sus chalets a la orilla del lago Coatepeque. Fue una conversión social. ${ }^{3}$

Y la segunda fue la reestructuración de los esquemas mentales del pensamiento religioso, desde la forma de entender a Dios y la iglesia que habíamos mamado en el catecismo hasta la forma de comprender al mundo y la trascendencia según el Vaticano II. Vivimos el Concilio en Innsbruck como si fuera un campeonato mundial de futbol. Pero no se trataba sólo de una competencia entre visiones del mundo dentro de la misma iglesia, sino de un desvestirse de las antiguas formas de pensar y un aceptar nuevas. Para nosotros, fue un teólogo genial, Karl Rahner, el que nos condujo de la mano desde la teología tradicional, que se encontraba en los libros de texto, a una comprensión de la iglesia y de la fe desde la experiencia del Misterio, al que llamamos Dios, palabra que siempre limita y que es como una moneda sucia que se usa para cosas opuestas. Rahner, a mí, en particular, me liberó de la ley. Nos hicimos subversivos contra lo que habíamos aprendido desde niños. Rahner nos enseñó a pensar, poniendo todo en cuestionamiento. Su método era arrancar siempre de la pregunta y batallar con ella y no temerle. Pero, no sólo llevar como criterio de verdad la lógica implacable, sino, de la mano con lo que nos había enseñado el maestro ecuatoriano de la ósmosis, encontrar el criterio de verdad en la paz y la consonancia interior. Lo que nosotros los jesuitas llamamos el método del discernimiento (Ver Vorgrimmler, 2004).

Con este bagaje experiencial e intelectual fui a estudiar antropología a los 35 años en Texas. Éramos varios jesuitas centroamericanos que fuimos enviados a estudios filosóficos y sociales en distintas universidades de Europa y Estados Unidos. Yo fui enviado a estudiar antropología. El más potente y líder de todos nosotros fue Ignacio Ellacuría que fue asesinado por el ejército salvadoreño, junto con otros cinco compañeros y dos mujeres, en 1989. Eramos utópicos y estábamos impulsados por un ansia de transformación del mundo desde nuestro trabajo intelectual y organizativo. Ese era el norte de nuestros estudios.

Yo fui a Texas buscando la guía de Richard Adams, antropólogo que había hecho trabajo de campo con estudiantes norteamericanos en Guatemala. Cuando yo llegué, sus estudiantes habían terminado de escribir y yo no me integré a ellos. Pero Adams no es un antropólogo de la religión. Otro antropólogo más joven me encandiló con Lévi Strauss. Este fue el primer influjo ya propiamente antropológico que recibí. Aprendí más o menos a desarmar los mitos y los parentescos. Además, a través de otro antropólogo, más materialista, fui encaminado a conocer los yaruros en Venezuela. Esa fue una experiencia muy impactante. Tres meses aguantando

\footnotetext{
Ferrán Manresa, de mente privilegiada y hoy con Alzheimer, citaba mucho a un teólogo francés que marcó una línea en la investigación teológica sobre el acto de fe y se llamaba Pierre Rousselot, contemporáneo de Marcel Mauss y van Gennep. Fue autor de un libro, Les yeux de la foi (1910), que el mismo Ferrán prologaría, traduciría y comentaría en 1994: Los ojos de la fe (1994), Ed. Encuentro. Según este autor, que tuvo un influjo enorme en la comprensión no racionalista de la fe en la teología católica, la fe no consiste en creer en una verdad abstracta, como sería la existencia de Dios, sino en una persona. No es un acto solamente intelectual, sino afectivo. No es privativa de gente letrada, sino la mismísima fe en toda su profundidad se encuentra en el pueblo que no sabe leer ni escribir. No hay fe de los teólogos y fe de la gente sencilla. En siendo fe, realmente fe, su estructura es la misma. Una consideración que cruza culturas.
} 
Encuentro №. 102, 91-107, 2015

hambre en la sabana venezolana junto a un afluente del Orinoco y aprendiendo en la convivencia con ese pueblo primitivo (entonces) los elementos de la sociedad donde el sistema de primos cruzados era clave. A la vez, eran los años de la estela que había dejado tras de sí la muerte del Che Guevara (1967). Me apasionó su diario y lo comparaba con la experiencia yarura, no por lo revolucionario, sino por el aspecto elemental de su vida. Y así llegué al examen comprensivo sobre antropología de la religión en que me pusieron a analizar un mito de no sé dónde y también me pusieron preguntas sobre la evolución de la religión. Me alabaron las respuestas de lo primero, pero consideraron que estaba crudo en lo segundo. Me hicieron repetir el examen. Lo cual me sirvió para tener en mente que no se puede considerar en el aire la cosmovisión, sin relacionarla con la evolución y el poder, entendido como adaptación al medio, en lo que el cuerpo teórico de Adams era fuerte, siguiendo a Leslie White. Y el poder, con la primacía de la tecnología, como mediadora entre el ser humano y el medio.

Así, con esta mochila en la espalda de cosas medio aprendidas, me tiré al trabajo de campo para la tesis doctoral. Fui a un pueblo kiché de Guatemala, llamado San Antonio Ilotenango, que aparece en el Popol Vuh como Ilocab, un conglomerado de linajes aliado a los Kichés. Orientado por Adams, iba a buscar el impacto de la demografía en la cultura de ese pueblo pequeño de unos siete mil habitantes en 1969. No iba a ser un estudio de antropología religiosa. Pero me encontré con un movimiento religioso de rebelión contra las creencias tradicionales que se había extendido a prácticamente todo el altiplano indígena de Guatemala y tenía como nombre Acción Católica. El núcleo de la rebeldía consistía en rechazar al que hoy se llama líder espiritual maya, en kiché aj q'ij. Junto con él se rechazaba su símbolo principal, el tz'ité (envoltorio de semillas del árbol de pito, rojas), y su práctica ritual de adivinación (ch'ob'onik), de acuerdo al calendario maya, todavía muy vivo en esos lugares. El movimiento se institucionalizó en centros fuertes que se erigieron en el hinterland de los municipios con una ermita y fue apoyado por un clero joven, extranjero en su mayoría, que había entrado a Guatemala después de la invasión desde Honduras del anticomunista Castillo Armas en 1954. Ante la realidad que tenía delante, Adams me permitió cambiar el tema de la tesis.

De allí vino el título de la tesis, La Conversión Religiosa, y del libro, Quiché Rebelde, que fue leído por el ejército como un texto subversivo y fue leído por la guerrilla como un texto de apoyo, ya que ese movimiento religioso, que había comenzado con un signo anticomunista serviría luego, a finales de los años 70, como cama organizativa para la organización campesina, y cuando la represión arreció en 1980, para su alzamiento en las filas guerrilleras del EGP (Ejército Guerrillero de los Pobres).

Pero en la tesis no atiné a imaginar cuál sería el puente entre ese movimiento religioso, que cuando yo lo conocí estaba todavía muy impregnado de conservadurismo, y la revolución. La tesis se ciñó a la explicación de por qué siempre el porqué por delante de toda investigación - por qué una tercera parte de la población había cambiado de creencias, mientras otra se había mantenido firme en la suya. Se trataba de un análisis del acto de fe en movimiento, tanto individual, como colectivo. Para responder al porqué, sin tener una teoría a la que siguiera paso a paso, fui buscando los factores demográficos, los tecnológicos (abono químico), los 
económicos (red de comerciantes), los sociales (reorganización de los matrimonios, los linajes, las nuevas estructuras de parajes y aldeas) hasta su representación política. Tenía un montón de datos después del trabajo de campo de un año y volví a Texas a escribir, lejos del bullicio y actividad de Guatemala, y no sabía cómo comenzar. Después de tres o cuatro meses de sentirme perdido - ustedes saben lo que es sentirse sin saber cómo comenzar a escribir frente a un cúmulo de información - después de varios intentos, decidí tirarme por el análisis de casos y escogí un par de personas que habían vivido dolorosamente el cambio de fe, para diseccionar su poder propio y su poder derivado, su poder real y su poder cultural (el que piensan que tienen), incluyendo en este último la creencia no experimentable (religiosa), todas categorías de Adams. Al par de esta mirada sincrónica, había que ver su proceso diacrónicamente desde que se iniciaba su crisis hasta que se completaba. Habiendo encontrado el hilo del análisis, pero sin terminar la redacción de la tesis, volví a Guatemala para irla completando en medio de las actividades de docencia que se me darían.

Pero en el análisis no bastaba el poder, puesto que el cambio de creencias lleva consigo un salto de adhesión total, lo que llamo la especificidad de la experiencia religiosa, y éste no se explicaba por el poder, tanto más que ese salto, el salto de la fe, implica, cuando se da en radicalidad, una negación del poder, como sucedía con las personas que decidían retirarle la adhesión total al líder espiritual maya arriesgándose a morir, ya que el líder les decía que si no hacían las ceremonias a las que renunciaban, morirían. Para ayudarme en la explicación de ese paso me fui a Victor Turner $(1967 ; 1969)$, al concepto de liminalidad que él había recogido de van Gennep (1909). Después, me serviría para enmarcar mi propia experiencia y la de los sobrevivientes de las masacres en su noche oscura.

\section{La noche oscura de la liminalidad: Esa muerte que nos hace vivir ${ }^{4}$}

Era el año 1978. Ya había terminado mi tesis (1974). Ya había dejado la academia en la Universidad Rafael Landivar de Guatemala. Ya nos habíamos involucrado cada vez más en un proyecto de lo que llamábamos los jesuitas el CIAS (Centro de investigación y acción social) en torno a la organización campesina. El terremoto de 1976, que había conmocionado las conciencias, había provocado también un repunte muy fuerte de la organización clandestina, todavía distinta de la campesina. Con un grupo de compañeros jesuitas trabajamos, en unión con otros agentes de pastoral, en la costa sur de Guatemala y a la vez en el altiplano. En la primera, se encontraban el trabajador ranchero y el proletario, por lo general no indígenas, de las grandes fincas de café, caña y algodón. En la segunda, el grueso de la población indígena, jornaleros temporales muchísimos de ellos. Buscábamos cómo realizar la alianza organizativa de ambas poblaciones en lo que después se llamó el CUC, Comité de Unidad Campesina.

4 Publicado en la UCA de El Salvador en 1984: Esa muerte que nos hace vivir. Estudio de la religión popular de Escuintla, Guatemala. 
Encuentro No. 102, 91-107, 2015

En eso, el obispo de Escuintla en la costa sur nos pidió hacer un estudio de la religiosidad popular de su diócesis. Pensamos que en esa religiosidad se encuentran chispas de protesta, de acuerdo a lo de Marx, que la religión es el opio del pueblo, opio que calma el dolor pero hace soñar, y que la religión es el llanto de la criatura oprimida, llanto que puede ser un grito, y aceptamos la demanda y nos organizamos, algunos jesuitas junto con un par de amigas antropólogas, para hacer la investigación.

De allí salió el librito que se publicaría en El Salvador, llamado Esa muerte que nos hace vivir, que terminé de escribir en la ciudad de México, anegado en llanto. Y es que en el trabajo de campo, cosa muy humana, nos enamoramos locamente con una de las amigas y en la lucha por discernir de mi vida salí de Guatemala para poner tierra de por medio. El dolor por el que pasé fue el mayor de mi vida, el de una noche oscura, como dice San Juan de la Cruz. En el proceso de discernimiento yo gasté mucha tinta reflexionando sobre mi vida. Pero a la vez tenía este compromiso con el obispo. Tenía que escribir algo. Y había cierta presión, porque teníamos otro compromiso, que era ir a apoyar cuanto antes a la revolución sandinista desde nuestras especialidades. Entonces, embargado en mi problema, no pude menos de trasladarlo a la interpretación de la religiosidad popular, como si fuera mi propio espejo. Qué me importa, dije, si no sigo normas establecidas de análisis. Pero sí las seguí, porque se me vino a la mente de nuevo Turner y su liminalidad, ya que yo mismo estaba en un estadio liminal, ni aquí, ni allá, o acababa de pasarlo, al decidir seguir en la Compañía de Jesús, a pesar de que otros compañeros la hubieran dejado. Entonces, fiché como en un mes de trabajo todo mi material y en una sola tarde estructuré todas las fichas, colocando el nacimiento y la muerte, como primeros capítulos, el primero, la entrada de la vida, y el segundo, la salida de la vida, dos umbrales, para los cuales hace falta una aceptación social.

No creo que falseé o violenté los datos con mi experiencia. En ellos no mencioné mi experiencia para nada, pero sí llené los datos con la experiencia, casi como si estuvieran para reventar. Myrna Mack, la antropóloga que fue apuñalada en 1990 por el ejército, me contaba que leería luego el librito y subrayaría el capítulo de la muerte, como si ella leyera un prenuncio de la suya. Ella conocía lo que había detrás de esas líneas. Ella conocía también Quiché Rebelde y debe haber notado que era la misma mente analizante, un caso u otro, pero que en Esa muerte que nos hace vivir, lo que yo decía no era oído, sino vivido. El título quedó así, porque hay muertes que son estériles, que no nos hacen vivir, pero hay otras que sí son vida, y que las estériles son las falsas muertes, que ordinariamente son las que buscamos, para usarlas como escudo frente a la muerte verdadera, la mía, la que me toca, que es MUERTE, y por eso la rehuimos, pero esa es la que nos da vida. En realidad, de esta crisis yo salí como resucitado, llorando a mares detrás de las paredes, a escondidas, pero nuevo, casi podría yo decir, reluciente, como se lo dije una vez a Ellacuría al volver de México a Centro América pasando por El Salvador, "Ellacu, ¡he muerto!" Pero estaba vivo. Y él, el gran líder y el de una inteligencia poderosa, así lo veíamos nosotros, sólo calló y admiró. Todavía me remueve. Ustedes han sentido lo que es esta muerte en vida. Ustedes me entienden. Aprovéchenla en sus estudios. No la divorcien de la vida. Las dicotomías son un enemigo perverso.

Con esa herida fui a Nicaragua en 1980 trabajando en la Reforma Agraria desde un centro de investigación llamado CIERA (Centro de Investigación y Estudios 
de la Reforma Agraria). No puedo extenderme a la experiencia de investigación en la Nicaragua Nicaragüita. Desde allí seguíamos con ojos revolucionarios el auge popular y guerrillero en Guatemala, pero también las masacres. Desde allí organizamos la vuelta a la patria con unos compañeros. Eso nos llevó a visitar los campamentos de refugiados en 1982 y constatar que las noticias de las masacres genocidas no eran una exageración. Tuve la suerte o el don de oír a uno de los sobrevivientes de una de esas masacres, cometida el 17 de julio de 1982 en una finca aldea llamada San Francisco del Municipio Nentón, situada junto a la frontera con México. Encontré a los sobrevivientes de la masacre en un ejido chiapaneco llamado La Gloria. Don Mateo nos contó - y yo lo grabé - cómo había sobrevivido después que apilaron sobre él los cadáveres de los hombres que habían matado ese día y cómo se había escapado después de hacer una oración a los muertos que lo rodeaban: "compañeros, ustedes ya están libres, no me agarren, déjenme ir en libertad”. Y sintió fuerza, se paró, se quitó las botas de hule, abrió la ventana del juzgado auxiliar donde se encontraba encerrado y, como una culebra, para que no lo oyeran los soldados que tocaban las grabadoras robadas de los ranchos, se escapó a México, donde al día siguiente lo recibirían los ejidatarios que lo conocían porque venía a cortar café a Chiapas. Yo le pregunté, "Don Mateo, ¿usted iba triste?” ¿Iba triste cuando iba caminando hacia el ejido? Había perdido muchos familiares. La masacre se había llevado 376 personas. "Don Mateo, ¿usted iba triste?”. Él me contestó, "No, no iba triste, iba como bolo, no sé si es de día o es de noche, voy sin comer nada, como si hubiera destazado un animal, voy sin sombrero". Yo, entonces, me di cuenta de que él iba en un estado de liminalidad, no sólo porque iba cruzando la frontera, sino porque no era de nadie, ya que su grupo prácticamente había desaparecido. Era el hombre de la noche oscura. Como yo. Pero con otro tipo de muerte. Él, sin aceptarla todavía, abrumado, como bolo, confundido. Y mi persona, ya del otro lado de la liminalidad. De ese lugar salí como bañado de sangre y redacté el desarrollo de la masacre de acuerdo a las tres partes de la teoría de Turner, la premasacre, la masacre y la huída del sobreviviente. Llevé esa buena noticia, porque era buena noticia su sobrevivencia, a la reunión de antropólogos de los Estados Unidos en la ciudad de Washington a fines de 1982.

Allí, juristas de Americas Watch nos dijeron que era difícil probar genocidio dada la cláusula del "como tal": destrucción parcial o total de un grupo étnico, racial, religioso, ¡como tal! Pero nos armamos de valor y montamos una presentación, metiéndonos tal vez en un coto ajeno, el de los juristas, para el Tribunal de los Pueblos en Madrid a principios de 1983. El Tribunal condenó al Gobierno de Guatemala de genocidio, pero ese dardo, viniendo de Madrid, donde el alcalde era un izquierdista, y viniendo en un momento en que la represión había disminuido en la ciudad de Guatemala, fue ignorado, como un dardito. Es otro campo de reflexión, pero no quiero desviarme, la aplicación de la antropología a los derechos humanos. Es buena, pero puede ser un corsé. 


\section{La fe en la revolución: Ixcán. El campesino indígena se levanta (Falla, 2015b)}

El encuentro con esa masacre enorme me hizo preguntarme por el proceso que había culminado en ese acto de represión genocida. ¿Cómo comenzó? ¿Cómo se unió el campesinado, especialmente de las áreas indígenas, a él? Como ya dije, al escribir mi tesis sobre San Antonio Ilotenango, Quiché, yo no logré imaginar cómo esa población podría algún día apoyar a un movimiento armado revolucionario.

En esos tiempos se nos abrió el Ixcán (guatemalteco) a un grupo que deseábamos hacer pastoral de acompañamiento al modo sugerido por Monseñor Romero y Ellacuría. Después de hablar con la guerrilla que controlaba la zona, entramos. El grupito tenía el objetivo pastoral de hacer presente a Dios en esa zona destituida de agentes de pastoral. Pero, yo entré no sólo para hacer trabajo pastoral, sino para responderme cómo se había iniciado ese proceso. Entré como antropólogo. ${ }^{6}$

El "así llamado" trabajo de campo consistió en estar durante cinco meses en 1983 y hablar con la gente que estaba bajo la montaña, preguntándoles cómo habían colonizado la selva desde 1966 hasta 1983 y cómo se habían incorporado en la organización que apoyaba a la guerrilla. Entre las razones que daban aparecía el factor religioso, no el único. Entonces, al escribir, junté toda la dinámica religiosa en un capítulo. Una de las cosas que se responden en ese capítulo es cómo se fue dando el proceso desde el no matar del mandamiento de la ley de Dios hasta el aceptar la realidad de la guerra. Era una guerra en que uno debía defenderse y debía atacar para lograr el objetivo revolucionario de la toma del poder y la transformación de la estructura social. Entonces, debía aceptar el acto de matar a una persona. El proceso mental no fue doloroso, como cuando se daba la conversión religiosa estudiada en la tesis, sino gradual y lento. El momento definitivo se sellaba con la incorporación en la organización clandestina de la guerrilla, aunque no fuera para combatir, sino únicamente para apoyar con tareas.

En cierta manera nosotros, sacerdotes que trabajamos en esa área de guerra, pasamos por un proceso semejante. No éramos combatientes, pero apoyábamos la guerra y la justificábamos. Evidentemente, la justificación del campesinado indígena y de nosotros, agentes de pastoral, no se daba en el aire; no era sólo una acto de argumentación, sino, como ya dije, tenía como correlato social el nexo organizativo. Influyó la Teología de la Liberación, pero ésta no concluía necesariamente en el apoyo a la lucha armada. En el caso del Ixcán, dos cosas fueron muy importantes. Una, influyó en el campesinado el que cuadros guerrilleros, con quienes los campesinos se encontraban bajo la montaña, les hablaran en clave religiosa y en su idioma de cómo Dios apoyaba la guerra y Moisés mismo la había practicado y les dieran el ejemplo de cómo de catequistas algunos habían pasado a ser guerrilleros. Una segunda: se

5 Es el volumen 3 (2015) de una colección de Escritos llamada Al atardecer de la vida... Escritos de Ricardo Falla sj. y editada por AVANCSO, URL y EDUSAC.

6 Ver Falla (2015a). En ese libro, escrito en 1994 y reeditado recientemente por EDUSAC, se explica la vida en la selva del Ixcán y la pastoral de acompañamiento. 
profundizó la aceptación de la guerra y se extendió con la experiencia de la represión del ejército. Ese sí fue un momento de gran dolor que convirtió al campesino indígena definitivamente hacia la guerra. Se involucró en tareas y su apoyo se hizo ya una realidad del diario vivir, como parte de una subcultura de resistencia, donde el elemento religioso era muy importante. Así también para nosotros, como agentes de pastoral de acompañamiento en la resistencia, la guerra fue una actividad en la que participamos, no como combatientes, ni tampoco como orgánicamente vinculados con la vanguardia (guerrilla), pero sí con toda el alma, haciendo presente a Dios entre las comunidades de población en resistencia (CPR, se llamaban).

Mucho se puede hablar sobre el papel de la fe religiosa en una guerra revolucionaria impulsada por dirigentes no religiosos, incluso algunos ateos que en sus campamentos enseñaban el marxismo leninismo.

Pero yo encontré otra realidad que estuvo presente en muchas de las masacres y que luego afloraba en la autodefensa durante la guerra. Era el uso del argumento religioso para no practicar la autodefensa impulsada por la guerrilla y para confiar en el ejército, so capa de ponerse en las manos de Dios. Así murieron muchos en 1982. No huyeron cuando el ejército se acercaba y fueron masacrados por él. ¿Por qué no huyeron? Ellos decían que se ponían en la mano de Dios. ¿Pero era esa la razón verdadera? Allí es donde la sospecha es siempre buena para analizar. Los compañeros, es decir, la guerrilla, decían que porque eran contrarrevolucionarios y no es que confiaran en Dios, decían, sino que confiaban en el ejército y por eso no huían. Si huían se declaraban enemigos del ejército y éste los perseguiría, y por eso no huían pensando que los tratarían bien, como amigos, por no haber huido. Pero se equivocaron. El ejército había perdido toda medida de discernimiento (iigenocidio!!) y los acabó. Pensó que eran mentirosos. No les creyó. Pensó que levantaban la biblia, pero secretamente le daban comida a la guerrilla. Y los acabó. En un próximo volumen, escrito hace 30 años y que pronto se publicará explico esto.?

\section{La espiritualidad maya: El Popol Wuj. Una interpretación para el día de hoy (Falla, 2013b)}

Quisiera entrar ahora a la investigación de una etapa más tranquila, la de la espiritualidad maya. (Esta parte de la conferencia fue prácticamente improvisada. Ahora la redacto. Véase abajo el Anexo, de lo que llevaba escrito.)

Salí del Ixcán porque el ejército encontró un buzón con mis papeles y debía informar a la iglesia de lo sucedido. El obispo de la diócesis no quiso ya que volviera y fui destinado a Honduras, donde permanecí desde 1983 hasta 2001. Ya firmada la paz en Guatemala volví, residiendo ahora en un pueblo kiché llamado Santa María Chiquimula, donde trabajo apoyando a la parroquia y escribiendo.

Al volver de Honduras encontré un movimiento bastante fuerte dentro de la iglesia de Guatemala de revalorización de la espiritualidad indígena. Habían influido en él, el aniversario de los 500 años (1992), el premio Nóbel concedido a Rigoberta

Véase también el artículo Martirio. Algunas reflexiones espirituales (2011) en Falla (2013a, pp. 351370). 
Encuentro No. 102, 91-107, 2015

Menchú y la Carta Pastoral de los obispos sobre la inculturación del Evangelio en las culturas autóctonas. En ella los obispos de Guatemala pedían perdón por el desencuentro de la conquista o invasión y se preguntaban cómo pagar la deuda de los costos de las masacres y violencia contra las culturas que había acompañado a la primera evangelización. También, en 1996 se firmó la paz y se ratificó el acuerdo ya firmado sobre los Derechos de los Pueblos Indígenas, donde se reconoce el derecho a su espiritualidad.

Encontré alrededor de la iglesia de Santa María Chiquimula un movimiento de revalorización de la cultura maya con relaciones hacia Chiapas en talleres de crecimiento en clave maya, talleres de Teología India y Ejercicios espirituales también en clave maya. Se formó luego un equipo llamado Qajb'al Q'ij (Occidente) que da talleres de espiritualidad maya, cuyos "horcones", como dicen, son el calendario maya y el Popol Vuh. Es decir, me encontré al volver de Honduras con algo muy distinto de 1970, cuando había vivido en el pueblo vecino de San Antonio Ilotenango. Antes, la iglesia fomentó el rechazo de prácticas importantes de la espiritualidad maya kiché, que ahora pretende apreciar y enaltecer.

Hemos insistido en enfocar el estudio del Popol Vuh en Santa María Chiquimula con maestros y maestras kichés, teniendo presente lo que el mismo texto dice, que es un ilb'al re, como un cristal en el que se ven e interpretan para la acción los acontecimientos. Es el mismo enfoque que don Samuel Ruiz recomendaba para la interpretación de la biblia, un ojo en el texto y el otro en la realidad, para que el texto ilumine la realidad y para que la realidad ilumine el texto. ${ }^{8}$

Pongo un ejemplo. En el último taller antes de la segunda vuelta de las elecciones nacionales para presidente y vicepresidente (25 de octubre recién pasado) nos preguntamos: ¿qué nos enseña el Popol Vuh? ¿Cómo debemos elegir entre los dos candidatos? Evidentemente, el Popol Vuh no nos va decir en concreto por quién votar, pero nos puede dar criterios y luces para no equivocarnos. Entonces, trajimos el pasaje en que los dos héroes Junajpú e Ixbalanké bajaron a Xibalbá y se encontraron con cuatro caminos. Ya sus padres se habían encontrado con los mismos, aunque tuvieran colores un poco cambiados, y ellos habían comenzado a ser derrotados allí. No supieron elegir. En cambio, los dos jóvenes, sí. Se metieron por el mismo camino negro de sus padres, pero con conciencia. Ellos conocían el interior de Xibalbá, porque su madre era de allí. La conciencia los llevó a darse cuenta de que inmediatamente después del cruce de caminos se encontrarían con los señores de Xibalbá y que era crucial conocerlos para no ser derrotados. Entonces, mandaron a un zancudo $\left(x a^{\prime} n\right)$ que se acercó al primero de todos los señores que estaban sentados en orden. Lo picó, pero no reaccionó. El señor era de palo, como un espantapájaros muy bien adornado, que parecía vivo. El zancudo fue al segundo, lo picó y tampoco reaccionó. También era de palo. Luego zumbó para picar al tercero y este reaccionó, “¡Ay!”, dijo. Y entonces el cuarto que estaba a su lado le preguntó, “¿Qué te pasó, Jun Kamé?” Luego, el zancudo picó al cuarto, quien también brincó y dijo, “¡Ay!”, y el que estaba a su lado le preguntó, “¿Qué te pasó, Wuqub’ Kamé?”, declarando su

8 "... el texto ilumina la realidad y en la misma realidad descubre el sentido del texto de una forma muy natural" (Ruiz García, 2003, p. 153). 
nombre espontáneamente como el anterior. Y luego picó al siguiente, y el de al lado le preguntó, cuando dijo “¡Ay!”, “¿Qué te pasó, Xikiripat?”. Y así sucesivamente, hasta que todos los nombres de los grandes señores de la muerte fueron revelados y los jóvenes no fueron derrotados porque habían conocido las identidades de todos ellos.

Las lecciones para la elección presidencial fueron muy sencillas. Una, que había que entrar por el camino de la muerte, el camino negro, pero a sabiendas de que nos encontraríamos siempre con muchas pruebas. Dos, que no fue en el cruce de caminos donde se encontraba la prueba, sino que las pruebas serían progresivas. Tres, que es necesario conocer la identidad de los candidatos a través de sus reacciones espontáneas. Cuatro, que esas reacciones espontáneas no se dan cuando se mueven en espacios políticos arreglados, porque les interesa proyectar una imagen, que no es la verdadera. Quinto, que no se va a elegir a un individuo, hombre o mujer para presidente, sino a todo un grupo o equipo. Y sexto, que el primero del grupo puede ser una figura muy engalanada, pero que detrás de él están los que de verdad mandan. Este punto resultaba muy importante para no dejarse llevar por la imagen atractiva del candidato comediante y descubrir detrás de él a los militares escondidos. Tal vez las lecciones no sirvieron mucho, porque sospecho que la mayoría de maestros y maestras jóvenes, que ya manejan las redes sociales, estaban encandilados con el famoso comediante Jimmy Morales. Pero sí les sirvió para comprender la realidad política y para conocer el texto como algo actual e importante.

Este es el método seguido en el libro El Popol Vuh. Una interpretación para el día de hoy, que está siendo usado en talleres de jóvenes mayas, mujeres y hombres, que ya dominan el arte de la escritura, como aparece en la portada y contraportada.

Nuestra idea de espiritualidad, sin embargo, no se ciñe al conocimiento del Popol Vuh o del calendario. La espiritualidad maya es algo más amplio. Les cuento un ejemplo. Se acaba de celebrar en la cumbre de Alaska, donde hace tres años el gobierno mató a seis indígenas kichés, el aniversario de esa fecha: 4 de octubre. La directiva de los 48 cantones de Totonicapán organizó la ceremonia y trajo a un líder espiritual de Chinique, Quiché. Cuando el fuego se estaba consumiendo, éste pidió que la directiva saturara sus varas junto al fuego. Entonces, uno de la directiva tomó el micrófono y dijo que "Yo no puedo pasar porque tengo otra fe". Era un evangélico. Todos quedamos un poco electrizados. Pero el aj q'ij dijo con calma que allí no se forzaba a nadie y que la espiritualidad maya tenía la capacidad de abrazar a diversas creencias y religiones.

Para terminar quiero dar tres posturas, muy generales por supuesto, que tal vez se pueden descubrir en la actualidad dentro de la iglesia católica de Guatemala frente a la espiritualidad maya. Las he encontrado a nivel de agentes de pastoral, incluso obispos, y a nivel de base. La primera es de incompatibilidad. Es decir, de aquellas personas que juzgan que existe una incompatibilidad entre la espiritualidad maya y el evangelio. Incompatibilidad es una forma elegante de decir que "eso es del diablo", "que no volvamos al pasado", que son "los extranjeros los que no quieren que progresemos y vienen a levantar esas cosas que ya estaban muriendo". Se refieren, sobre todo a la concepción de espiritualidad más ceñida a creencias y ritos tradicionales, como el calendario maya, pero también abogan por que la 
Encuentro №. 102, 91-107, 2015

espiritualidad en sentido más amplio se deje morir.

Una segunda es la del diálogo interreligioso. Ven a la espiritualidad maya como otra religión, al estilo del hinduismo, donde se reconoce que está presente Dios, pero que es distinta del cristianismo y del catolicismo. Con ella hay que dialogar, pero no se deben dar confusiones y sincretismos. Esa tendencia es una expresión de la interculturalidad. El diálogo entre ambas tradiciones religiosas debe darse para fortalecer la lucha por la justicia en el mundo y en Guatemala y la lucha por el medio ambiente, como aspecto de esa misma justicia.

Y una tercera, que es la de una inculturación del evangelio que lleva a casi una identificación entre la espiritualidad maya, entendida en su sentido estricto, y la espiritualidad cristiana. Un ejemplo, la anterior no admitiría el que un católico, ni menos un sacerdote, practicara el calendario maya. En cambio, esta sí. Esta identificación, más práctica que teórica, tiene como consecuencia cierta dicotomía, y es que las mismas personas que son sujeto de la espiritualidad maya distingan en la práctica los espacios donde se practica. Si estamos en un taller de espiritualidad maya, no mencionamos a Jesucristo. Si estamos en una misa, nos ajustamos al rito católico occidental, aunque se le adorne con formas litúrgicas mayas, como el altar en el piso de los cuatro puntos cardinales.

El objetivo de la inculturación consiste en que el mensaje del Evangelio llegue hasta las raíces de la cultura. Según ella, el Evangelio no es ajeno o extraño a ninguna cultura del mundo, ya que desde la creación están en ellas las semillas del Verbo. Entonces, cuando el Evangelio se acerca a ellas, empata con ellas como con algo propio. Eso sí, lo que hace falta para que se dé este empate es que el Evangelio se desnude de la cultura occidental y de los paradigmas colonizadores inconscientes y profundos de los que son portadores sus agentes. Por eso, no podrá haber una profunda inculturación si el sujeto de esa inculturación no es el mismo pueblo. Y no podrá haber una profunda inculturación, si no hay una actitud crítica, tanto frente a la propia cultura de la que se desprende el Evangelio al inculturarse, como frente a la cultura en la que se incultura.

La inculturación es aceptada por las tres tendencias mencionadas, pero de distinta manera. El punto que hace la diferencia es el entendimiento de la cultura y la espiritualidad maya. La primera considera algunos elementos de la misma como incompatibles, la segunda, como distintos, y la tercera, como abiertos al Evangelio. $O$ puesto de otra forma, la primera considera que esos elementos no forman parte de las semillas del Verbo, la segunda, que sí, pero están superados por la revelación cristiana, y la tercera, que sí, pero que no están superados.

Eso sí, me parece que en el tratamiento del hecho religioso no podemos ser ingenuos. En toda expresión religiosa, occidental o maya, hay engaños. Por eso mismo, en la investigación del hecho religioso no se puede admitir una actitud neutral, libre de valores. La misma investigación debería llevar en sí la crítica de la religión y de su espiritualidad. Las lecciones del marxismo en este terreno nos son muy provechosas.

Se podría intentar describir las posturas del movimiento maya frente al cristianismo. Probablemente se dan imágenes que son espejo de las anteriores. Pero ya no tenemos espacio para seguir adelante. 


\section{Conclusiones: a modo de pixab' de un jabalí de pelo blanco $^{9}$}

Acerquémonos sin miedo a la investigación del hecho religioso, aunque hayamos renunciado a la fe religiosa y no sepamos al principio cómo manejarla. Tal vez queremos negarla y nos incomoda un poco que en el ambiente religioso de nuestros países se nos imponga el lenguaje religioso por todos lados.

Acerquémonos en lo posible sin prejuicios. Siempre nos quedaremos cortos. Las personas muy fervientes suelen pensar que poseen la verdad y que no pueden aprender de las demás, sino que tienen que comunicar tal cual lo que viven.

Acerquémonos con humildad, nosotros como antropólogas y antropólogos, a encontrar la sabiduría del pueblo, pero no perdamos la sospecha de que por todos lados las ideologías se esconden detrás de lo religioso. Humildes, pero no ingenuos. Si bien, en el hecho religioso hay semillas de rebelión y transformación hacia la justicia, también hay engaño. A veces el engaño es craso y fácilmente desmontable, a veces es muy sutil, y nos involucra a nosotros mismos en nuestro afán crítico. Sin embargo, también hay que advertir que es muy fácil y resbaladizo el tránsito de la actitud crítica a la hipercrítica. La hipercrítica, al hacer filo al lápiz, quiebra la mina.

Acerquémonos también con apoyos teóricos. Si tenemos la capacidad, desarrollemos la teoría a partir de los grandes autores, pero no nos despeguemos de la realidad y de la praxis. Quizás uno de los principios teóricos para distinguir la autenticidad de la experiencia religiosa es que no hay fe auténtica sin una exigencia de justicia. Y para nuestro trabajo, no en Europa, ni Estados Unidos, ni en Rusia..., sino aquí en América Latina, pensemos si es posible una transformación social profunda sin las motivaciones religiosas. Recuerdo las palabras de Fidel Castro en Managua al año de la Revolución Sandinista, es decir, en 1980. Dijo algo así, imaginándose la cadena volcánica que recorre todo el istmo centroamericano: cuando se junta la fe religiosa con la revolución entonces hay una erupción.

Por fin, acerquémonos al hecho religioso como Manuel Castells se acerca al hecho social, sin casarnos definitivamente con ninguna teoría, apegándonos, eso sí, tal vez Castells no lo diga, al dato interior de la experiencia, de modo que al hacer investigación la hagamos con la inquietud de comprendernos a nosotros mismos desde el espejo de la realidad. ${ }^{10} \mathrm{Si}$ es el caso, sin miedo a perder mi fe atea, porque si es auténtica, se profundiza, porque el ateísmo, el humilde, está enraizado en la mente humana. Creo yo, pues....

R.Falla sj

9 Pixab' en kiché se llama a los consejos de las gentes mayores.

10 En el prólogo a su obra en tres volúmenes, La era de la información, Castells dice: "Y, sí creo, a pesar de una larga tradición de errores intelectuales a veces trágicos, que observar, analizar y teorizar es un modo de ayudar a construir un mundo diferente y mejor" (2002, p. 30). Observar, analizar y teorizar en continua interacción. Y en su "perspectiva teórica" postula la organización de la sociedad por un tríptico de relaciones: de producción, de experiencia y de poder (p. 40). Y, en cuanto a la experiencia, dice, "la experiencia se estructura en torno a la relación de género/sexo, organizada en la historia en torno a la familia y caracterizada hasta el momento por el dominio del hombre sobre las mujeres" (p.41). 